SOCIAL SCIENCE AND PUBLIC POLICY

\section{Debt and the American Dream}

\author{
Eric Best
}

Published online: 30 May 2012

(C) Springer Science+Business Media, LLC 2012

Recently the markets for American housing and American education have changed significantly. There are seemingly endless explanations for the growing debt levels surrounding housing and education. Many of these explanations involve irrationality or "bubbles", implying that market actors do not understand what is occurring. This paper argues that debt markets for mortgages and college education in the United States are in fact defective by design, and function exactly as intended. Mortgages and student loans, used to finance the modern American Dream, have become so deregulated and subsidized that the markets for housing and education are fundamentally changed. These markets are not experiencing bubbles, they are experiencing continued growth rates due to easy access to debt and incentives to borrow. The markets for the American Dream ideals of home ownership and college education have experienced similar stages of development: deregulation by federal law and subsidies for borrowing, unintended industry growth, and finally industry fraud.

The debt markets for mortgages and student loans in the United States were created and bolstered by a willing government and a credulous population, both intent on feeding the misguided modern American Dream of continued upward mobility for all. Home ownership and college education have been identified as signals of middle class living in America, and there is broad support for making them widely available. However, home ownership and a college education are expensive propositions, both implicitly and explicitly. Continually increasing the percentage of Americans

\section{E. Best $(\bowtie)$}

Disaster Research Center,

Graham Hall, Room 166, 111 Academy St.,

Newark, DE 19716, USA

e-mail: ericbest@udel.edu who own homes or attend college means providing opportunities to people with increasingly inadequate means to afford repayment. Because of this, continued growth requires relaxed regulations for loans in the housing and education markets. In most circumstances, deregulation proposals of consumer debt markets are hotly debated in the legislative branch of government, but the "American Dream" classes of debt enjoy open encouragement of deregulation by both major political parties. The lack of barriers of issuance for mortgages and college loans created environments for home and student lending totally out of proportion to traditional constraints on debt. When even more growth was required and deregulation was not enough, the government stepped in and actually began to subsidize borrowed money for home loans and college education. Conditions for these types of debt became so relaxed that the housing and education markets were fundamentally changed because of consumer access to plentiful subsidized loans.

\section{All Bubbles Are Not Created Equal}

Traditionally, asset bubbles are identified as irrational behavior leading to a continual growth of demand for an asset. Throughout modern history, there are numerous cases of asset bubbles appearing, including examples such as tulip mania from the 1600 's, early American currencies in the 1800 's, and the dot-com boom in the late 1900's. These were cases where the belief in future price growth caused market participants to sharply drive up asset prices. After the fact, commentators point out that prices were out of line with fundamental values, and that the market was taken over by speculators anticipating the existence of greater fools. The assets oftentimes do not have traditional fundamental values related to their bubble prices, and demand and price 
fall rapidly after the bubble bursts. Final purchasers are left with goods that are not desirable on the market, and future investors, with no incentives to stay in the market, disappear.

In contrast, American Dream assets-housing and education-enjoy a different set of circumstances. In addition to future benefits (home values and increased income from education), there is a positive social signal sent by home ownership or college education that lasts over time. The benefits of home ownership and college education are deeply engrained in American culture. However, what truly differentiates the markets for the American Dream goods from other bubbles are the economic incentives provided by the government to continually increase demand for homes and education by constantly creating laws that create incentives for suppliers of these goods, and the creation of subsidies to boost demand for these services. Additionally, the American Dream goods are often purchased with borrowed funds on long-term debt plans, meaning that "investors" in the goods are locked in, and cannot quickly abandon the market. Based on social stigma, government involvement in deregulation, subsidies, and longterm repayment agreements, American Dream assets exist in fundamentally different markets from traditional bubble assets.

\section{Deregulation and Subsidization}

It is comical to imagine a politician in the United States running on a platform of reduced home ownership and decreased access to college education. Home ownership and education are considered sacred ideals, and support for them is almost universal. Because of the inability of elected officials to openly oppose growth in these areas, the United States has fostered legislation that encourages "predatory lending". Throughout the last few decades, law after law has passed with two-party agreement making it easier to buy a home or go to college.

Laws for home loans such as the Community Reinvestment Act of 1977 (CRA), the Financial Institutions Reform, Recovery, and Enforcement Act of 1989 (FIRREA), the Riegle-Neal Interstate Banking and Branching Efficiency Act of 1994, and the Financial Services Modernization Act of 1999 all contributed to increased home ownership. Laws for student loans such as the Higher Education Act of 1965 (HEA) and the Federal Direct Student Loan Program of 1993 (FDSLP) fundamentally changed access to college. Amazingly, the Higher Education Opportunity Act of 2008 even tied the number of low interest college loans made to low income students into the standards for CRA compliance, practically forcing banks to participate in subsidized lending for both American Dream assets. These laws have been upheld and "modernized" constantly by both Republican and Democratic congresses and presidents. The American Dream asset growth satisfies both political parties because they allow for increased access to resources for the economically disadvantaged (favored by Democrats) while simultaneously resulting in significant financial deregulation (favored by Republicans). Many of these laws include direct consumer subsides to lower the cost of borrowing with the intention of boosting consumer demand for education and home loans. The subsidies, usually accomplished by making the interest for loans tax-deductible or deferred, made it seem much cheaper for consumers to enter into loan agreements to enable home ownership or college education.

In fact, support for the American Dream assets is so strong that Fannie Mae, Freddie Mac, and Sallie Mae were created as quasi-governmental lenders designed to increase access to home ownership and college education through more relaxed borrowing. American Dream assets are the only class of assets for which the government has created separate businesses to finance directly to consumers. While it is difficult to imagine a quasi-governmental organization chartered to provide loans for consumer electronics or automobiles, organizations devoted to expanding the market for American Dream goods flourished. These powerful policies and organizations result in a system of unprecedented deregulation which allows consumers access to amounts of debt that would be impossible to finance for any nonAmerican Dream goods, coupled with government subsidies designed to increase demand. This combination has created a completely modified market for American Dream goods with incentives to raise both supply and demand for mortgages and student loans.

\section{Unintended Industry Growth}

American homebuilders and higher education institutions have not ignored the reduced barriers to entry in their markets, and have engaged in a decades-long boom by creating ever more attractive and extravagant homes and education opportunities. Deregulation coupled with lending incentives redistributed so much money into housing and higher education systems that those industries have not only responded by creating more homes and schools, but by creating more expensive ones. Because most consumers are able to borrow money to finance housing or education, they are less sensitive to price, and therefore look at education and housing opportunities based on features. The original intention of getting more people in homes and in college quickly becomes overshadowed by getting people in more extravagant homes and schools. This has lead to an explosion of home and education amenities, resulting in houses and colleges that bear little resemblance to those in the memories of previous generations. American Dream legislation and incentives have created a market where 
homes have almost doubled in size and colleges frequently recruit students with increasingly luxurious lifestyle amenities instead of focusing on academic pursuits.

Incentives for education and home ownership do not work exactly as intended. Although the easy access to debt undoubtedly helps more people buy homes and attend college, it also encourages would-be students or homebuyers to consider more expensive options. Thanks to long payback periods, teaser rates, and delayed repayments, there are few immediate disincentives to choosing more expensive education and housing options. This results in American Dream industries that compete on features instead of price, becoming increasingly farther removed from the original intentions of the laws to promote opportunity.

The buildups in features-bigger houses and amenities for students-occur because the immediate cost to consumers is almost invisible. Over a 20 -year student loan repayment term or a 30 -year mortgage, borrowing another $\$ 10,000$ hardly seems bothersome. Because students and homebuyers can spread out the costs over long periods of time (if they even have to consider them immediately) there is a tremendous incentive to choose options that are more luxurious instead of options that are cheaper. Homebuilders and universities have been happy to create more luxurious houses and campuses to better compete for consumers armed to the teeth with borrowed funds.

\section{Industry Fraud}

While industry response to increased demand is an important but common market reaction, widespread industry fraud is a unique response to the incredible amounts of money available to providers of American Dream assets. Consumers with modest means and often little understanding of repayment are given access to huge loan amounts for American Dream assets, amounts that would not be available to them to finance other goods. Home loans without down payments and student loans covering all of tuition are available to people who would have a difficult time getting a credit card with a four digit limit. This presents a unique opportunity for these industries not available to other retailers: access to financially unsophisticated customers with access to huge amounts of borrowed funds that can only be used to purchase American Dream assets, often with cash back. This paradox encourages consumers in dire financial straits to demand American Dream goods even when they, and their lenders, likely know that they will be unable to meet their future debt obligations. In some cases, consumers are buying goods and services in which they may not even be interested.

Government and societal pressure to get people into homes and students into college is so great that largely fraudulent practices frequently occur in American Dream industries. Examples of these practices include loan amounts in excess of cost (loan-to-value ratios above $100 \%$ ) in the mortgage industry, and the rise of for-profit universities that survive almost completely on part-time students funded exclusively with student loans. In both of these cases, consumers can be given loans larger than their current obligations with little oversight about how they are spent. These terms encourage consumers with little ability to repay loans to apply for and accept home and education loans to obtain houses or educations that they may not intend to keep or finish. Until the recent mortgage crisis, mortgage lenders were perfectly willing to extend loans to utterly unqualified applicants under the assumption that the securitized house would end up being worth more than the defaulted debt. Because an education is worth nothing as security to a lender, the federal government self-insures federal student loans. These practices mean there is little incentive for the American Dream industries to care about the quality of housing or education provided to these marginal applicants.

Housing and education markets diverge slightly here, because mortgages are paid in full to home sellers up front, but education loans are distributed by academic semester. While a home seller has no reason to care about a home buyer after the payment is processed, universities have to make sure paying students can come back semester after semester. Because most for-profit universities to not have the same traditions, research focus, accreditations, and admissions standards, there is little incentive for these universities to be selective about their student bodies. Instead of enduring the competitive application process at not-forprofit universities, prospective for-profit students are courted with high-pressure sales tactics, encouraging them to join the institution and making them aware of the prospect of loan funds resulting in cash in hand. These for-profit universities actually hope students will take cash back loans because this is often the hook that keeps students coming back even if they do not want the education provided. The for-profit institutions rely on loan money almost exclusively, and want to recruit as many students as possible and retain them for as long as possible until the students reach maximum student loan amounts.

The failures of "liar" home loans and for-profit education are apparent when looking at loan default rates. The downturn of the housing market has made everyone aware of the high default rates of marginal mortgage applicants, but the student loan default rates have not yet earned as much attention. According to a recent Department of Education study, for-profit universities are responsible for educating $12 \%$ of college students, but those students are responsible for $48 \%$ of student loan defaults. This means that for-profit universities are responsible for graduating students who frequently have no chance of repaying their loans. Because these loans are often backed by the government, the organizations are essentially defrauding taxpayers. 
While fraud is not unique to American Dream industries, the amount of money lent to individuals with little chance of being able to repay loans puts them in a class by themselves. Incentives to obtain payment are so great and the barriers to entry so low that volume is one of the only considerations of the darker side of the American Dream industries. Securitization, government incentives, and subsidization have created a market where the ability to repay is hardly examinedan ideal circumstance for fraud.

\section{Are There Other American Dream Industries?}

While the markets for home loans and education loans are extremely similar, and many lessons about education loans can be drawn from the recent implosion of the mortgage industry, there are other industries that have similar traits. The obvious case is health insurance. Arguably, the country benefits if more people have health insurance, there are individual benefits to health insurance, and thanks to enhanced access industry services and fraud have skyrocketed. However, insurance models differ from home and education loans because the costs in the United States are distributed from the beginning, and because there has never been two party consent about constantly increasing the levels of the insured at the federal level. Insurance incentives and regulations in the United States are most frequently accomplished at the state level, reducing the likelihood of country-wide asset buildups. However, insurance is increasingly being viewed as a necessary means to upward mobility because of the risk of financial ruin due to individual medical costs. If the population starts demanding access to insurance as means to fulfill the American Dream of good living, we are likely to see another hasty marriage of federal legislation aimed at boosting numbers through unprecedented deregulation.

There are extensive bodies of popular literature about mortgages, student loans, and insurance, but surprisingly little is written about the similarities in legislation, incentives, and market cycles of American Dream assets. American Dream industries are created when access to a good or service is viewed as fundamental to upward mobility and quality of life. In fact, past American Dream assets, now viewed as simple basics in the United States, are currently targets of aspiration in other countries. Heavy tax breaks for car buyers in rural China follow a very similar formula to mortgage interest deductions and student loan subsidizations in the United States. It is virtually assured that there will be other American Dream goods, complementing the middle class ideals of home ownership and college education in the United States, but as a culture we appear unprepared to make the connection.

Eric Best is a Ph.D. student in the Disaster Science and Management program at the University of Delaware. 